\title{
Surface Roughness Modification of Free Standing Single Crystal Silicon Microstructures Using KrF Excimer Laser Treatment for Mechanical Performance Improvement
}

\author{
Mohamed Elwi Mitwally ${ }^{*}$, Toshiyuki Tsuchiya1 ${ }^{1}$, Osamu Tabata ${ }^{1}$, Sherif Sedky ${ }^{2}$ \\ ${ }^{1}$ Department of Micro Engineering, Kyoto University, Kyoto, Japan \\ ${ }^{2}$ Zewail City of Science and Technology, Cairo, Egypt \\ Email: ${ }^{*}$ melwi@nms.me.kyoto-u.ac.jp
}

Received 6 October 2014; revised 19 November 2014; accepted 5 December 2014

Copyright (C 2015 by authors and Scientific Research Publishing Inc.

This work is licensed under the Creative Commons Attribution International License (CC BY). http://creativecommons.org/licenses/by/4.0/

(c) (i) Open Access

\begin{abstract}
Single crystal silicon freestanding structures for tensile and fatigue testing were treated with $\mathrm{KrF}$ excimer laser to improve surface roughness and accordingly mechanical performance. Sample thickness was $5 \mu \mathrm{m}$. Localized laser treatment was successful in eliminating the scallops developed during Bosch process and in reducing surface roughness. Harsh irradiation at laser energies up to $4 \mathrm{~J} / \mathrm{cm}^{2}$ was only possible due to localized treatment without significant vibrations occurring on the freestanding samples that led to fracture in preliminary experiments at energies as low as $0.16 \mathrm{~J} / \mathrm{cm}^{2}$. Finite element analysis was used to investigate the temperature distribution on the irradiated structures. Atomic force microscopy (AFM) and Raman spectroscopy were also used to assess surface roughness, crystallinity changes and surface stresses developing on surfaces subjected to perpendicular laser irradiation. At a high energy $\left(3.2 \mathrm{~J} / \mathrm{cm}^{2}\right)$ the top surface showed a decrease of roughness compared to fabricated samples. Raman spectroscopy showed the dominance of crystalline silicon after laser irradiation. The effects of laser energy, number of pulses and angle of inclination of the irradiated surface on the resulting morphology were investigated.
\end{abstract}

\section{Keywords}

Freestanding Mechanical Test Structures, Harsh Laser Treatment, Surface Roughness Improvement

\footnotetext{
${ }^{*}$ Corresponding author.
}

How to cite this paper: Mitwally, M.E., et al. (2015) Surface Roughness Modification of Free Standing Single Crystal Silicon Microstructures Using KrF Excimer Laser Treatment for Mechanical Performance Improvement. Journal of Surface Engineered Materials and Advanced Technology, 5, 28-41. http://dx.doi.org/10.4236/isemat.2015.51004 


\section{Introduction}

Silicon is an abundant engineering material that can be processed into high purity grade miniaturized structures. Accordingly, it has been used extensively in the field of micro-electro-mechanical systems (MEMS). Some MEMs applications like micro sensors, optical mirrors and others require that the fabricated silicon structures endure mechanical loads; static or dynamic. One of the main factors affecting mechanical performance of single crystal silicon (SCS) structures is thought to be the fabrication process [1] [2]. The effect of the etching method used to fabricate SCS samples on tensile performance was investigated by Yi et al. and it was noticed that the value of fracture strength varied according to the resulting sidewall roughness [1]. Similar observations were made by other researchers who found that fatigue and fracture strength decreased with increasing roughness of sidewalls for polycrystalline and SCS beams [2] [3]. Accordingly an improvement in surface roughness of sidewalls resulting from the fabrication process should lead to better mechanical performance.

Different techniques have been investigated for surface roughness reduction of SCS structures. Laser irradiation has been employed for having waveguides with smooth sidewalls as well as for repairing damages resulting from machine cutting using a diamond tool of silicon wafers to eliminate dislocations and reduce surface roughness [4]-[8]. In other studies, hydrogen annealing of silicon structures resulted in smoother sidewalls [9] [10]. Smoothing through dry and wet oxidation has also been used [11] [12]. It is crucial to assess the limitation of each technique reported in literature to decide which would be more suitable for improving surface roughness and accordingly mechanical performance. Smoothing using hydrogen annealing and oxidation both involve subjecting the whole chip or wafer to high temperatures up to $1100^{\circ} \mathrm{C}$ [9]-[12]. This however represents a problem when dealing with chips that may have metallic or polymeric components that might be damaged due to such high temperatures. On the other hand, laser irradiation seems to have an edge over other techniques. It is possible to control laser spot size, location where the treatment is needed, pulse duration and wavelength. Laser treatment at the device level after all fabrication steps have taken place would also mean that no further damage would be introduced due to fabrication after the treatment. It would be less costly to have the treatment done at the device level due to yield factors.

Laser treatment of silicon wafers and supported structures has been used for decades and the effect of the treatment was studied extensively. Only recently laser treatment has been used on freestanding microstructures and was mainly used for the purpose of curvature adjustment of silicon cantilevers or for solving cantilever beam stiction problems using nanosecond and fem to second lasers [13]-[16]. Laser energies were however kept below the melting threshold with mainly perpendicular irradiation of top or bottom surfaces being investigated. It was claimed that high laser energy processing of freestanding microstructures would lead to thermal gradients across the thickness of samples which is quite risky since high temperatures would mean high strains near the surface of cantilevers that can reach the material's yield strength. For improving mechanical performance of freestanding structures, roughness reduction of sidewalls is the main concern. High laser energies above melting threshold would be required for that purpose since the smoothing mechanism of laser treated sidewalls depends on surface tension driven flow of molten silicon [4]. Another concern for laser treatment of sidewalls is related to efficient exposure to laser since neighboring structures could easily shadow sidewalls and prevent full exposure. For structures having corners or notches on sidewalls, the effect of laser treatment conditions on notch profile is also an issue that is investigated in the current study. The objective of this research is to optimize laser treatment conditions to improve surface roughness and accordingly mechanical performance of fabricated freestanding single crystalline silicon mechanical test structures. Mechanical test results after laser treatment are discussed elsewhere [17]. In order to avoid fracture of the annealed structures at high energies, localized laser treatment was employed so that only the location of interest would be irradiated. A special experimental setup has been used for the sake of efficient exposure of the sample sidewalls. Effects of laser energy, number of pulses and angle of tilt during irradiation of surfaces of freestanding structures are investigated.

\section{Experimental Method}

SCS beam structures were fabricated on a (100) silicon-on-insulator (SOI) wafer while being oriented along the $<110>$ direction. There are two types of the structures subjected to laser treatment. The first type is the tensile test sample that is shown in Figure 1. It has a square cross section of $5 \mu \mathrm{m} \times 5 \mu \mathrm{m}$ and a gauge length of $120 \mu \mathrm{m}$ [18]. The second type is the fatigue test sample that is shown in Figure 2. The beam has a width of $10 \mu \mathrm{m}$, a thickness of $5 \mu \mathrm{m}$ and a length of $30 \mu \mathrm{m}$. It has a notch at the midsection of the beam [19]. The sidewalls of both 

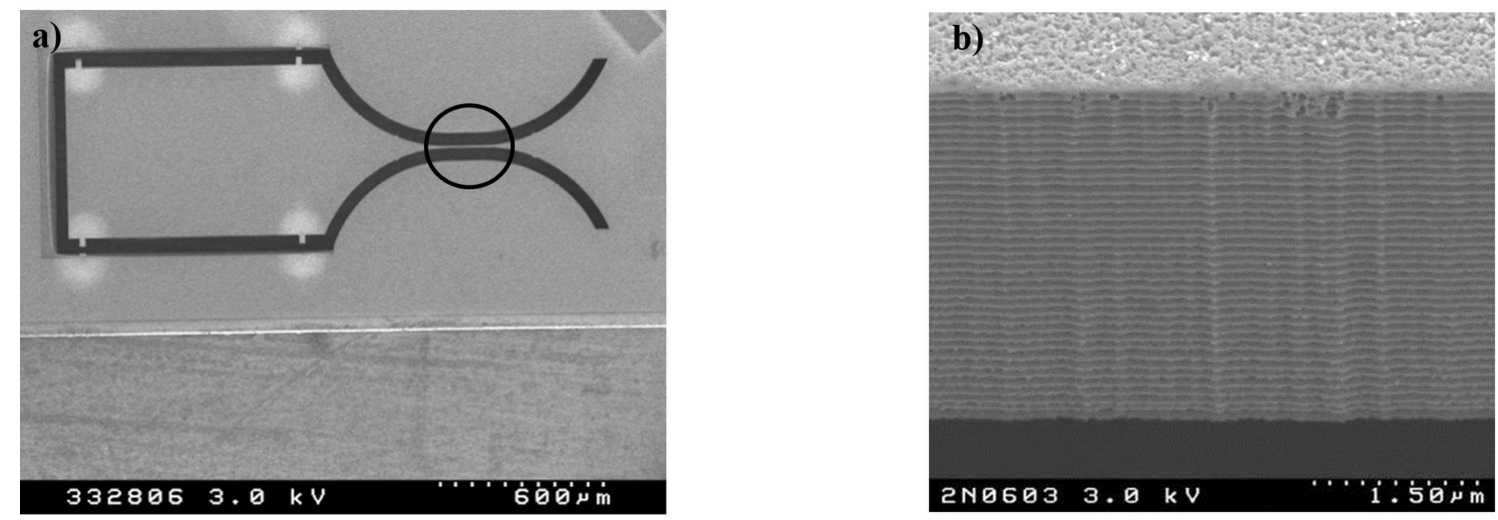

Figure 1. Tensile test sample. a) Whole sample and b) sidewall surface.
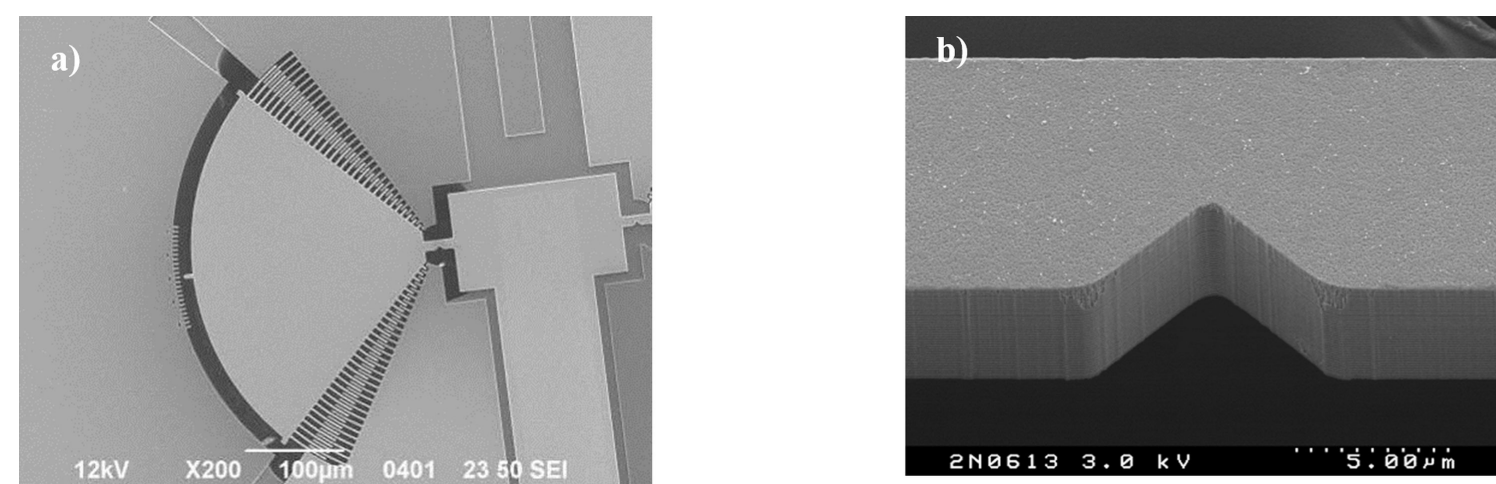

Figure 2. Notched fatigue test sample. a) Whole sample and b) notched beam.

samples have scallops caused by the Bosch process as shown in Figure 1(b) and Figure 2(b).

Samples were irradiated using a Coherent LAEX-1000 KrF (248 nm) excimer laser source with a pulse duration of 30 ns. The laser spot has a homogenous energy distribution over the spot size within 5\%. The spot size at the mask is $20 \mathrm{~mm}$ square and the reduction ratio used is 8 leading to a spot size of about $2.5 \mathrm{~mm}$ square at the sample surface. A mask is used to control the spot size to have localized laser treatment. In preliminary trials no mask was used leading to a spot covering the whole chip carrying the structures. The mask was used later on to decrease the spot size to $250 \mu \mathrm{m} \times 100 \mu \mathrm{m}$ for tensile test samples to cover only the gauge length while for the fatigue samples it was reduced to $100 \mu \mathrm{m}$ square to cover only the notch area. The energy values varied between $0.8 \mathrm{~J} / \mathrm{cm}^{2}$ and $4 \mathrm{~J} / \mathrm{cm}^{2}$ and the number of pulses varied between a single pulse and 1000 pulses. The pulse rate was kept constant at $1 \mathrm{~Hz}$. All the experiments were done in air at $1 \mathrm{~atm}$ and at room temperature.

For tensile test samples perpendicular irradiation of top surfaces have been used to investigate basic effects of laser irradiation on freestanding structures at different laser energies and number of pulses. Crystallinity, stresses, roughness and surface features were investigated. Figure 3 shows the as fabricated top surface for tensile test samples. The effect of tilt angle on sidewall morphology has also been investigated using $45^{\circ}$ and $65^{\circ}$ which is the maximum possible tilt angle without shadowing from neighboring structures. Figure 4 is a schematic of the test setup used for sidewall irradiation of tensile as well as fatigue test samples.

Crystallinity and resulting stresses on the top surfaces were evaluated using micro Raman spectroscopy (HORIBA Jobin Ybon, Labram HR-800) using Ar laser (488 nm) having a spot size of $1 \mu$ m. Three locations along the top surface of the laser treated gauge length of tensile test samples were used for Raman spectroscopy assessment. Curve fitting and smoothing techniques were used for the resulting Raman spectra and quantitative analysis was used to evaluate the relative significance of the amorphous and crystalline silicon phases present. A ratio was defined as

$$
r=\frac{I_{a}}{I_{c}}
$$




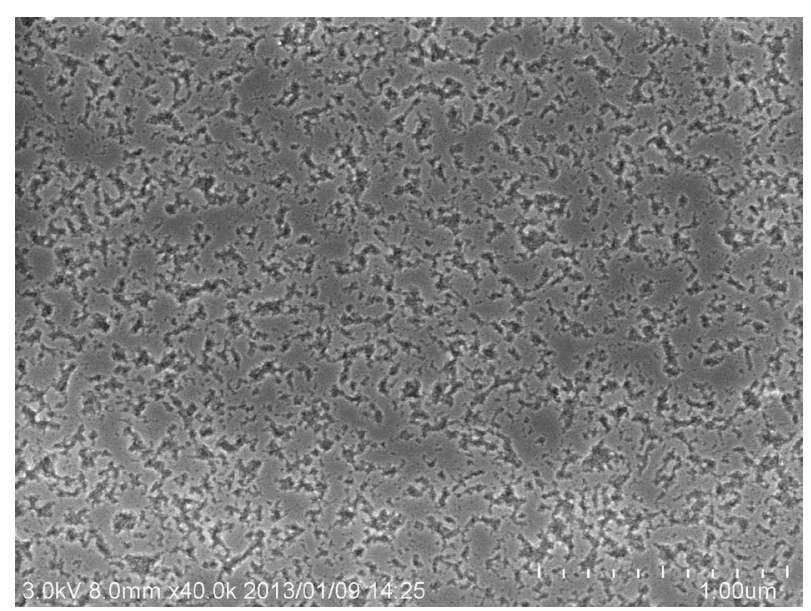

Figure 3. As fabricated top surface of tensile test samples.

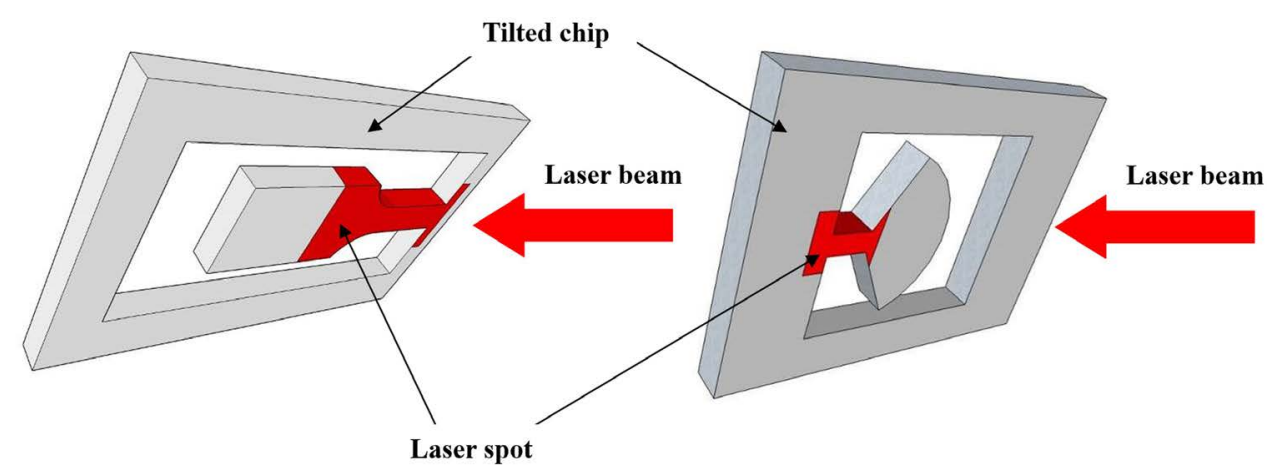

Figure 4. Experimental setup to irradiate sidewalls of samples.

where $I_{a}$ is the sum of areas under peaks representing amorphous silicon while $I_{c}$ is that of crystalline silicon after area normalization. This method is suggested by Yan et al. [6]. To assess surface topography, atomic force microscopy (AFM, Nanowizard III) was used. The change in surface average roughness for the top surfaces was examined for a scanned area of $1 \mu \mathrm{m}^{2}$ near the center of the sample width.

For the fatigue test samples, only sidewalls including the notch area were irradiated since the cracks are supposed to initiate at the notch [20]. In case of laser irradiation from top, the heat affected depth would not cover the sidewalls and accordingly tilting the test sample was needed. Various combinations of laser energy and number of pulses were mainly used to investigate the effect on sidewall and notch morphology. The whole chip was tilted by a fixed angle of $65^{\circ}$.

Finite element analysis (FEA) was conducted to evaluate temperature distribution due to laser irradiation using ANSYS. The FEA model developed is a 3D model that is governed by the Beer-Lambert equation

$$
I(z, t)=(1-R) I_{o}(t) \frac{e^{-z / \delta}}{\delta}
$$

where $I(z, t)$ is the laser intensity at a depth $z$ from the surface and time $t, R$ is the reflectivity, $I_{o}(t)$ is the laser intensity at the surface and $\delta$ is the penetration depth of $\mathrm{KrF}$ laser in silicon taken to be $6 \mathrm{~nm}$ [21]. The simulation considered temperature distribution due to irradiation with a single laser pulse of $1.6 \mathrm{~J} / \mathrm{cm}^{2}$ over a length of $13 \mu \mathrm{m}$ along the longitudinal direction of the fatigue test sample starting at the notch tip. Different material properties were used for silicon in solid and liquid phases as shown in Table 1.

Sidewalls and top surfaces of tensile and fatigue test samples were observed using field emission scanning electron microscopes (FESEM); Hitachi SU-8000 and S-4500 to assess morphology.

Observations made on tensile test samples and fatigue test samples will help come to an understanding of the effect of different irradiation parameters on the freestanding structures at hand. 
Table 1. Material properties used for solid and liquid phases of silicon during FEA simulation.

\begin{tabular}{ccc}
\hline Material Property & Solid Silicon & Liquid Silicon \\
\hline Thermal conductivity $\left(\mathrm{W} \cdot \mathrm{m}^{-1} \cdot \mathrm{K}^{-1}\right)$ & 148 & 200 \\
Density $\left(\mathrm{kg} \cdot \mathrm{m}^{-3}\right)$ & 2320 & 2500 \\
Heat capacity $\left(\mathrm{J} \mathrm{kg}^{-1} \cdot \mathrm{K}^{-1}\right)$ & 710 & 680 \\
\hline
\end{tabular}

\section{Results for Tensile Test Samples}

\subsection{Morphology Assessment of Top Surfaces and Sidewalls}

Preliminary experiments with no mask led to fracture of resonators at laser energies as low as $0.16 \mathrm{~J} / \mathrm{cm}^{2}$. Localized laser treatment for irradiation of released silicon structures was successful by controlling the spot size. Laser irradiation with energy values that go up to $4 \mathrm{~J} / \mathrm{cm}^{2}$ was achieved without fracture. For energies higher than 4 $\mathrm{J} / \mathrm{cm}^{2}$, samples fractured even for single pulse treatments.

In order to investigate the effect of number of laser pulses during perpendicular irradiation, a single pulse of 2 $\mathrm{J} / \mathrm{cm}^{2}$ sample was compared with a 10 pulses sample. Figure 5 shows the top surface morphology. The single pulse sample has a trench at the middle of the beam that disappears at 10 pulses. For higher energy values, no trenches were observed even for single pulses. This observation suggests the occurrence of thermocapillary (Marangoni) flow and indicates the development of a temperature gradient along the surface whereby the center has a higher temperature than the edges. This in turn causes the flow of molten silicon towards the edges having a higher surface tension. Although perpendicular laser irradiation is supposed to cause a homogenous temperature distribution on the top surface, it might be that the temperature gradient developing along the sidewalls would cause the molten liquid at the highest temperature near the top surface to move downwards along sidewalls. This would mean a decrease in the temperature at the top edges and could cause a temperature gradient development on the top surface whereby the edges would have a lower temperature than at the center. Marangoni flow on the top surface seems to be only a transient effect since no trench is observed at higher energies or number of pulses corresponding to longer melt times. An explanation of this behavior has been proposed in literature that Marangoni flow pushes molten silicon outwards causing a depression at the center region and heightening the liquid elsewhere until the surface temperature gradient decreases. At that point capillary forces will dominate due to surface deformation and will restore the shape of the surface pushing the liquid silicon back to the center until the trench congeals at sufficient melt time. Depending on the cooling rate, the shape of the solidified surface will be decided which will be that of the solidified melt [22]-[24].

In order to investigate the effect of laser energy on morphology, topography, crystallinity and developing surface stresses, different samples were treated at different laser energies with the number of pulses kept constant at 10. FESEM images for top surfaces are shown in Figure 6. No change in morphology could be noticed up to 2.8 $\mathrm{J} / \mathrm{cm}^{2}$ (Figure 6(b)) when particles start to form on the surface at the midsection. As the laser energy increases, these particles move further to the edges while the top surface roughness seems to improve in the central region as can be seen in Figure 6(c) and Figure 6(d). It was also noticed the center regions of the beam became darker than the edges. Such observations were also made by Nayak et al. who observed that Gaussian laser irradiated silicon has a central dark smooth region where the temperature is highest followed by particles on the rim and these particles were thought to be laser ablated particles depositing on the surface [25].

In order to investigate the effect tilt angle on sidewall morphology, two samples were irradiated at $45^{\circ}$ and $65^{\circ}$ while laser irradiated using 10 pulses of laser at $4 \mathrm{~J} / \mathrm{cm}^{2}$. The sample irradiated at $65^{\circ}$ also had perpendicular irradiation of the top surface at the same laser conditions to evaluate irradiation at $0^{\circ}$ as well. Figure 7 shows the cross section of both samples after being fractured in tensile tests. Looking at the three irradiated surfaces, it seems that an increase in tilt angle causes a skew in mass distribution. The irradiated top surface shows a symmetric profile while both sidewalls show an increase in width near the bottom surface that gets more significant as the tilt angle increases.

\subsection{Topography Assessment of Top Surfaces}

Figure 8 shows the surface morphology for as-fabricated and selected laser treated samples after leveling and 

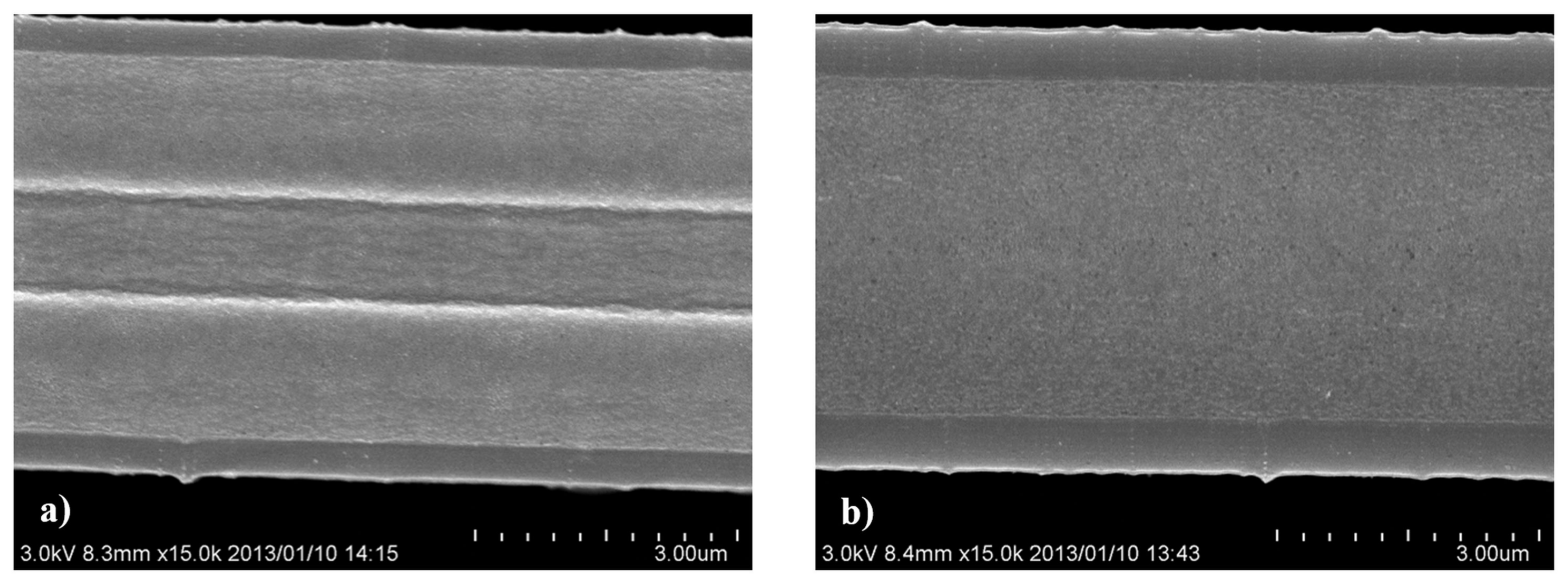

Figure 5. Topsurface of a tensile test sample subjected to $2 \mathrm{~J} / \mathrm{cm}^{2}$ of laser energy for a) one pulse \& b) ten pulses.
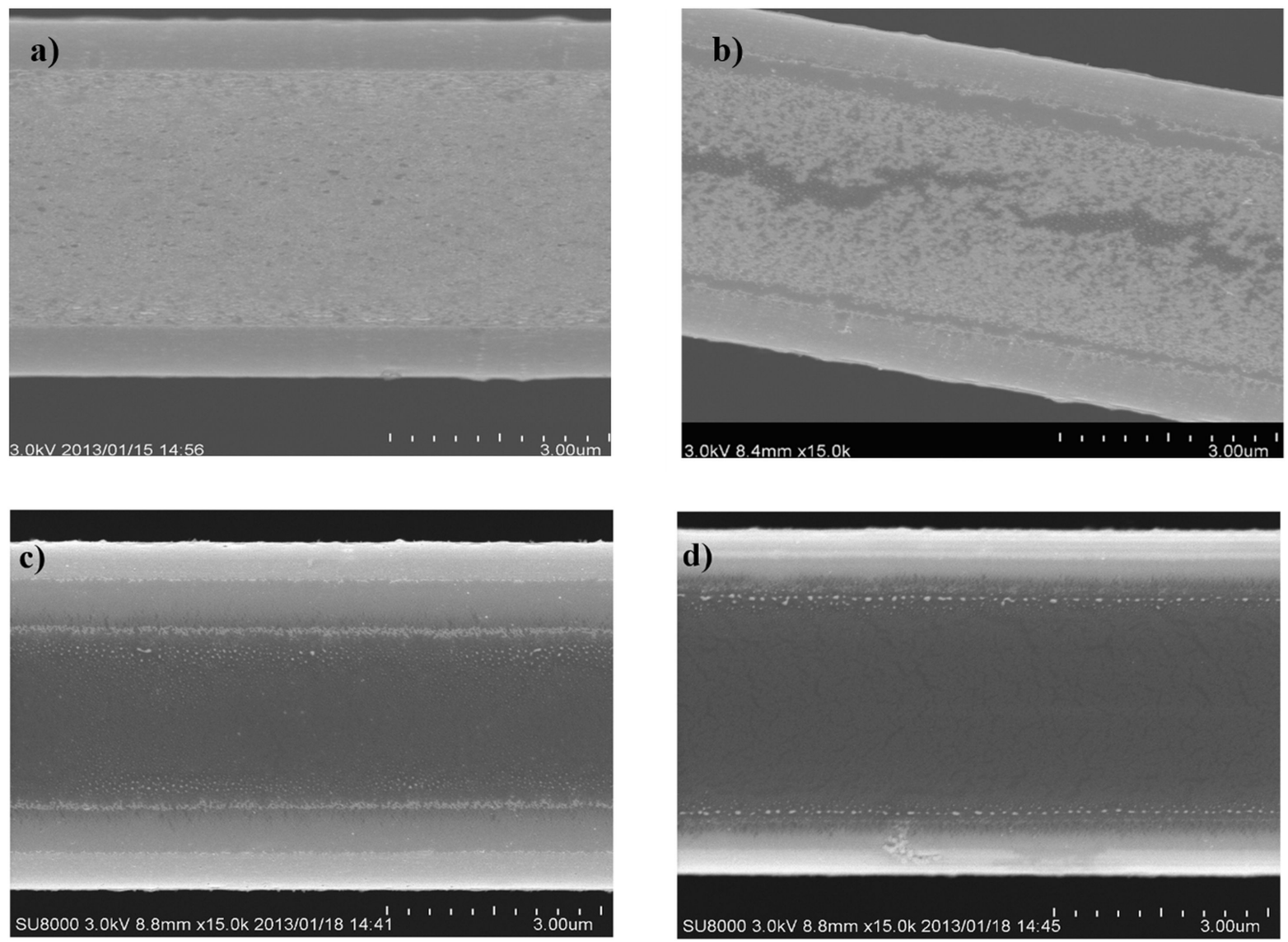

Figure 6. Laser treated top surfaces of tensile samples for 10 pulses at a) $2.4 \mathrm{~J} / \mathrm{cm}^{2}$; b) $2.8 \mathrm{~J} / \mathrm{cm}^{2}$; c) $3.2 \mathrm{~J} / \mathrm{cm}^{2}$ and d) $4 \mathrm{~J} / \mathrm{cm}^{2}$.

curvature adjustment while Figure 9 shows different values of average roughness corresponding to different laser energies. Roughness values showed a general decrease with laser energy with the sample irradiated at 3.2 $\mathrm{J} / \mathrm{cm}^{2}$ showing the minimum roughness $(2.28 \mathrm{~nm})$ which was an improvement over the as fabricated sample roughness $(2.86 \mathrm{~nm})$. The only exception in roughness value was for the sample irradiated at $2.8 \mathrm{~J} / \mathrm{cm}^{2}$ which showed a significant increase in roughness $(13.1 \mathrm{~nm})$. This could be due to particle formation at the midsection as indicated earlier. The roughness of a particle free area for that value of laser energy is also shown in Figure 9. All laser treated surfaces showed significant curvature compared to the as fabricated surface. 

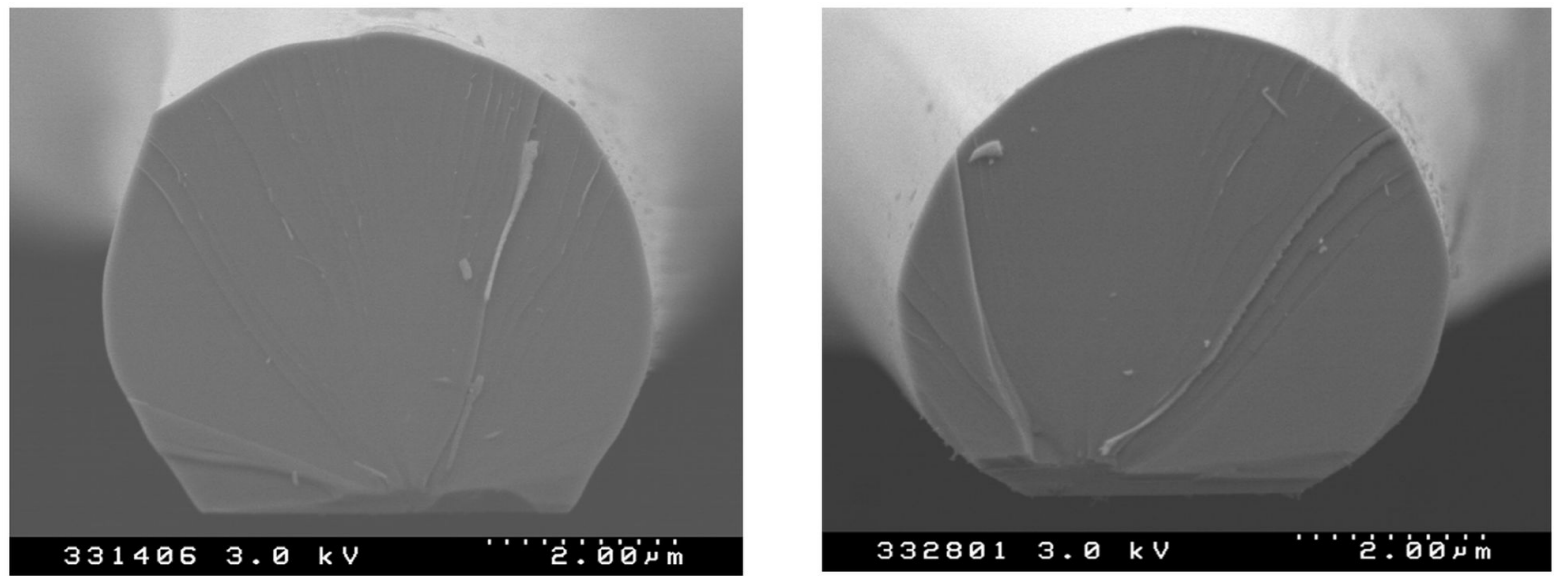

Figure 7. Laser treated samples at $4 \mathrm{~J} / \mathrm{cm}^{2}$ for 10 pulses at tilt angles of a) $45^{\circ}$ and b) $65^{\circ}$.

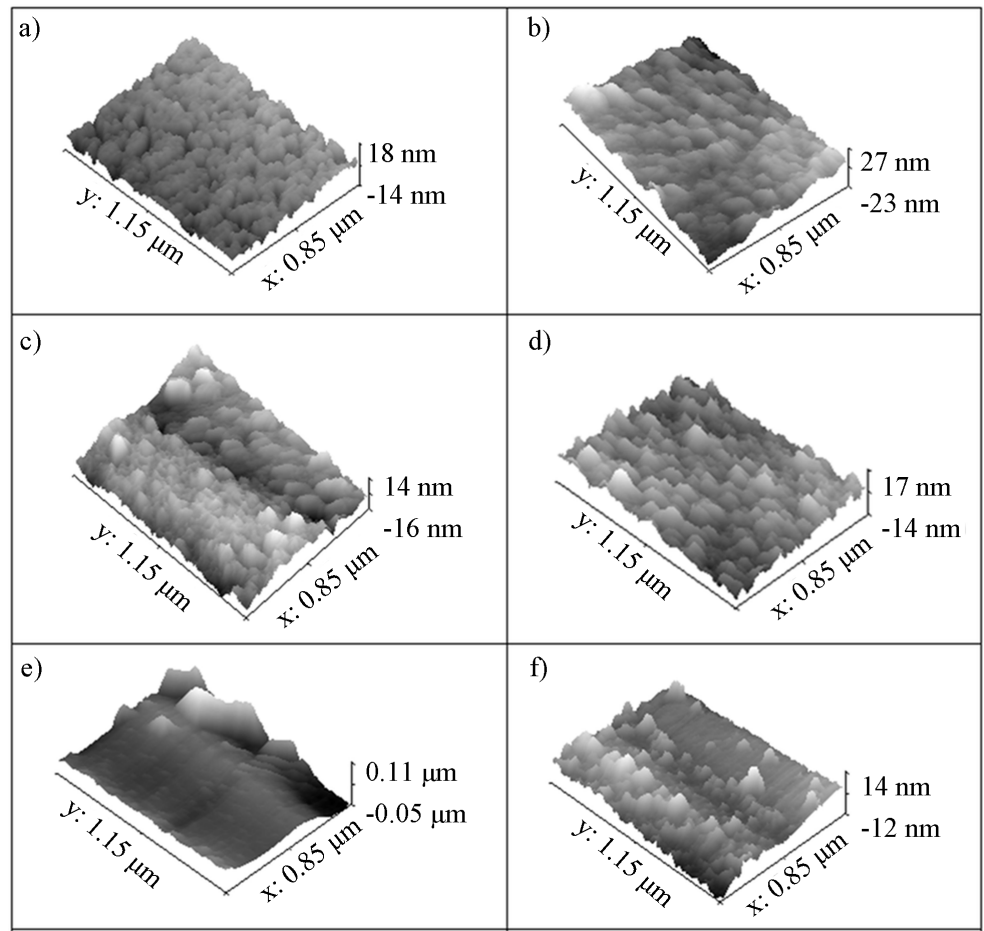

Figure 8. Surface profiles for a) as fabricated and laser annealed samples at b) $1.2 \mathrm{~J} / \mathrm{cm}^{2}$, c) $1.6 \mathrm{~J} / \mathrm{cm}^{2}$, d) $2.4 \mathrm{~J} / \mathrm{cm}^{2}$, and e) $2.8 \mathrm{~J} / \mathrm{cm}^{2}$ and f) $3.2 \mathrm{~J} / \mathrm{cm}^{2}$ with 10 pulses

\subsection{Crystallinity}

Figure 10 shows the representative dominant peaks for single crystalline silicon for as fabricated and selected laser treated samples. The most dominant peak for crystalline silicon occurred at alocation of $520.7 \mathrm{~cm}^{-1}$ for as fabricated samples. All laser treated samples showed that peak indicating the preservation of a crystalline structure. The $r$ ratio was calculated for all laser treated samples and it had a maximum value of 0.02 while reached a minimum value of 0.005 for the sample treated at $4 \mathrm{~J} / \mathrm{cm}^{2}$. This means that the amount of amorphous silicon is not significant with the crystalline phase being dominant for the all laser treated samples. During the laser treatment of silicon, laser melts the upper top surface while the solid layer beneath acts as a seed layer for the growth of a single crystalsilicon layer [6].

Figure 11 shows the resulting data for peak shift and normalized change in peak width with respect to that of 


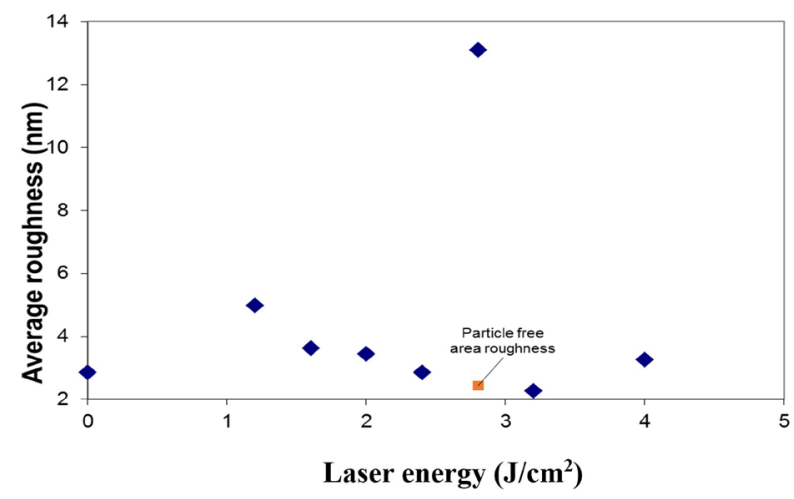

Figure 9. Average roughness values for different laser energies with a 10 pulse treatment.

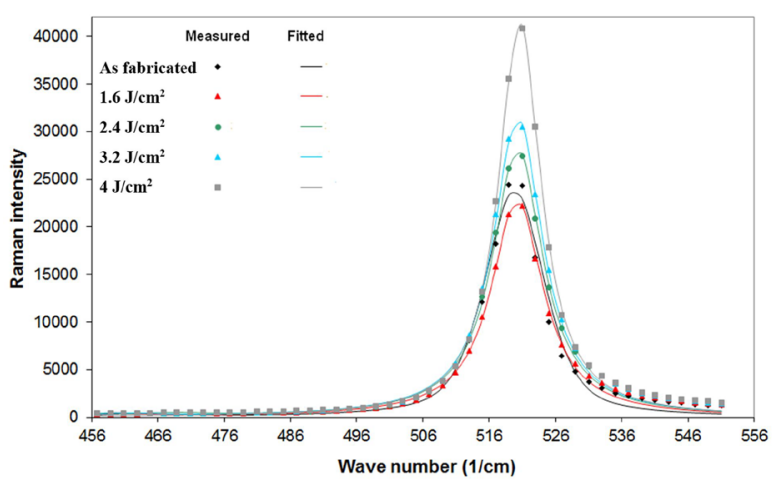

Figure 10. Raman spectra for as fabricated and laser irradiated tensile samples at different laser energies at 10 pulses.

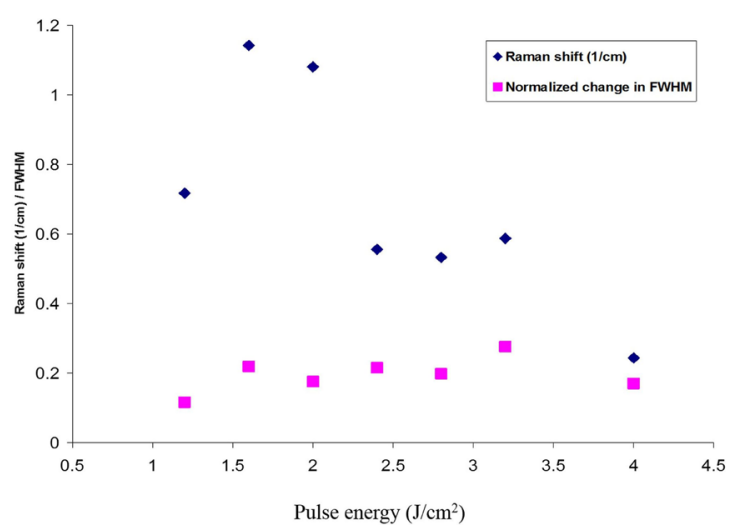

Figure 11. Change in normalized FWHM and Raman shift for different laser energies at 10 pulses.

the crystal silicon peak of as fabricated samples. The dominant peak has shifted to the left for all irradiated samples indicating tensile stress development on the surface. The shift showed a general trend of decrease with laser energy especially for energies above $1.2 \mathrm{~J} / \mathrm{cm}^{2}$ at which a maximum shift of $1.14 \mathrm{~cm}^{-1}$ was observed corresponding to tensile stresses of about $570 \mathrm{MPa}$ [26]. FHWM remained fluctuating around an average of $0.2 \mathrm{~cm}^{-1}$ with a standard deviation of $0.05 \mathrm{~cm}^{-1}$. During the heating cycle, the hot material is trying to expand but is being constrained by the surrounding cool region causing compressive stresses. During the cooling cycle on the other hand the hotter material is trying to contract but is being pulled by the surrounding hot region resulting in tensile stresses as the end result [27]. 


\section{Results for Fatigue Test Samples}

\subsection{FEA Temperature Distribution Results}

Figure 12 shows temperature distribution for a single pulse of laser at $1.6 \mathrm{~J} / \mathrm{cm}^{2}$ at the point of maximum temperature. Maximum temperature reached is $1963 \mathrm{~K}$ at the top edge which is above the melting temperature $(1687 \mathrm{~K})$ indicating that melting has occurred along sidewalls. The temperature is highest near the top surface and decreases with depth. The temperature at the notch tip is lower than the surrounding area and lower than the melting point of silicon.

\subsection{Irradiation Energy, Number of Pulses and Morphology Changes}

Figure 13 shows resulting morphology due to different combinations of laser energy and number of pulses. Up to $1.2 \mathrm{~J} / \mathrm{cm}^{2}$ sidewalls show improvement in roughness whereas the notch area did not improve. Sidewalls showed better roughness only at top edges while scallops were still present at lower parts. This agrees with the FEA where top edges had higher temperature than the rest of the sidewall. Furthermore, columnar structures grew in a direction parallel to the laser beam with 1000 pulses or more. These structures occurred through ablation and deposition [28] [29]. For energy values ranging from $1.6 \mathrm{~J} / \mathrm{cm}^{2}$ to $2.4 \mathrm{~J} / \mathrm{cm}^{2}$, the roughness of the notch area improved significantly without much distortion to the notch shape indicating melting at the notch. Temperatures in the notch area of the FEA model however did not reach the melting temperature of silicon (1687 K). This might be due to a lower reflectivity value used in the model since it is based upon assuming polished surfaces which is not true for the silicon sidewalls that have considerable roughness due to the scallops present. Vertical ridges were also observed at the tip of the notch at intermediate energy values $\left(1.6-2.4 \mathrm{~J} / \mathrm{cm}^{2}\right)$. At higher energies and multiple pulses $\left(3.2 \mathrm{~J} / \mathrm{cm}^{2}, 10\right.$ pulses), these ridges disappear as can be seen from Figure 13(j).

A white line is also observed across the notch area and sidewalls of certain samples up to $2 \mathrm{~J} / \mathrm{cm}^{2}$. The line however moves further downwards, fades away and completely disappears with higher laser energies and pulses. The tilt angle causes the development of a temperature gradient along the sidewalls with the top corner having the highest temperature as can be seen from Figure 12. It is expected that the white line appearing on sidewalls is caused by Marangoni flow pushing molten silicon from the top to the bottom edge along the sidewalls as indicated by the white line moving downwards as the laser energy and number of pulses increase as seen from Figure 13. From Figures 13(c)-(e) the white line moves downwards as the number of pulses increases from 10 to 50 but doesn't seem to move any further as it increases to 100 at $1.2 \mathrm{~J} / \mathrm{cm}^{2}$. As the laser energy increases, however, the line moves further downwards as can be seen from Figure 13(c), Figure 13(g) and Figure 13(h) with the white line totally disappearing at higher energies above $2.4 \mathrm{~J} / \mathrm{cm}^{2}$ as can be seen in Figure 13(j). At such energies however, a significant increase in notch tip radius occurred.

\section{Discussion}

Laser irradiation on free standing SCS microstructures was successful in improving roughness of the sidewalls

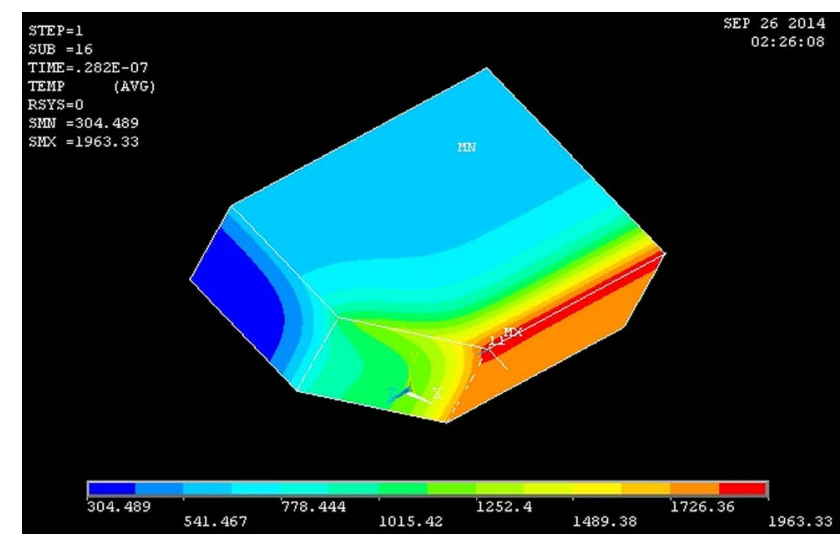

Figure 12. Temperature distribution due to a single laser pulse at $1.6 \mathrm{~J} / \mathrm{cm}^{2}$. 


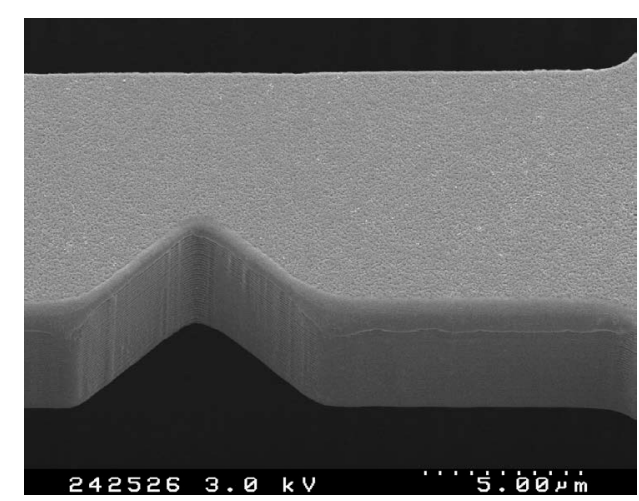

(a)

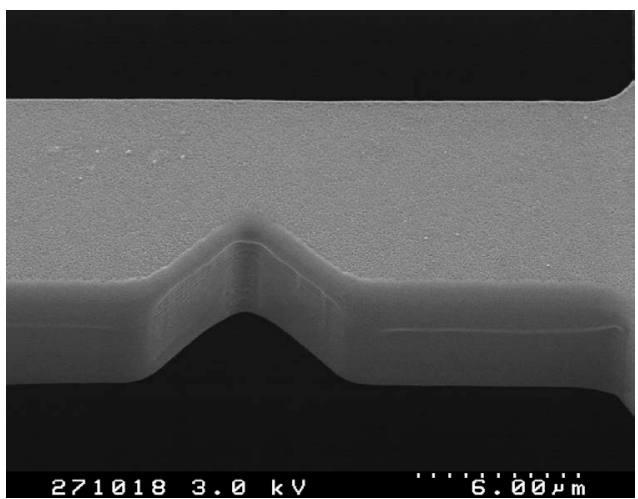

(c)

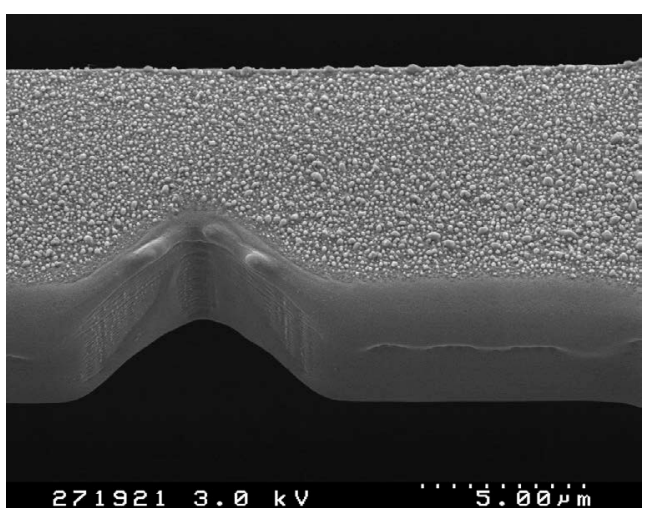

(e)

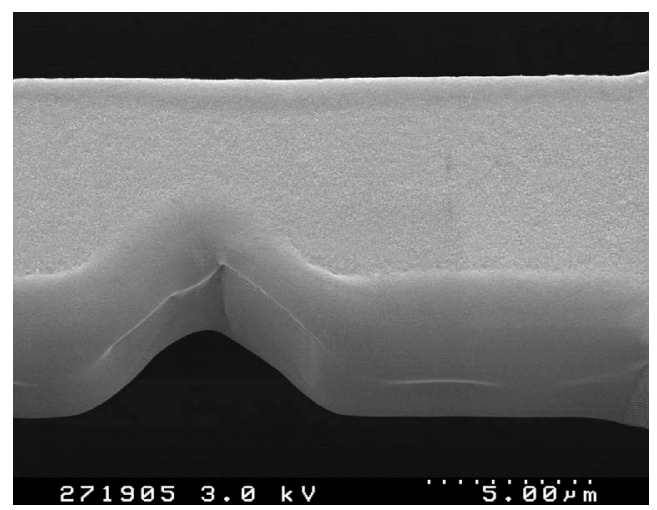

(g)

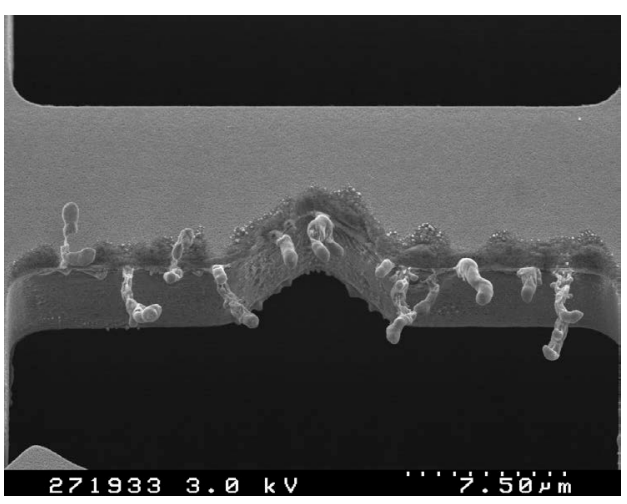

(b)

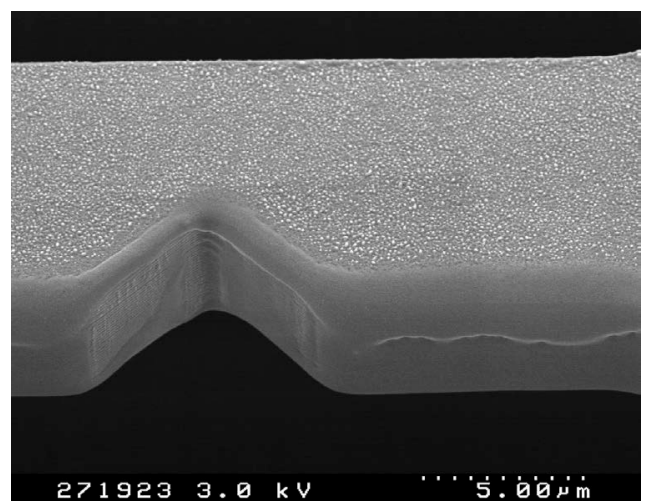

(d)

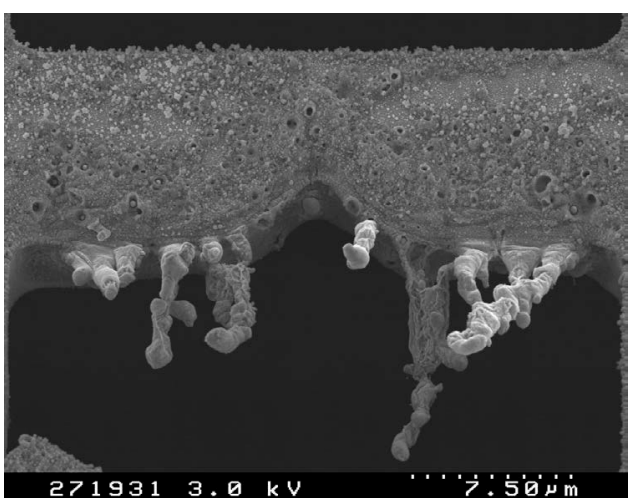

(f)

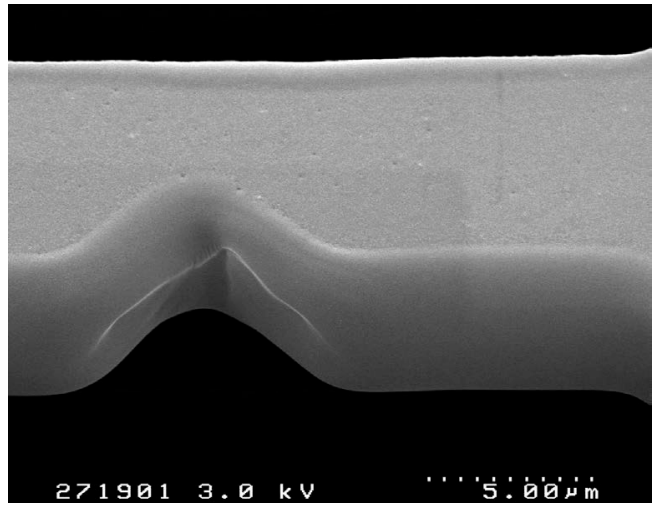

(h) 


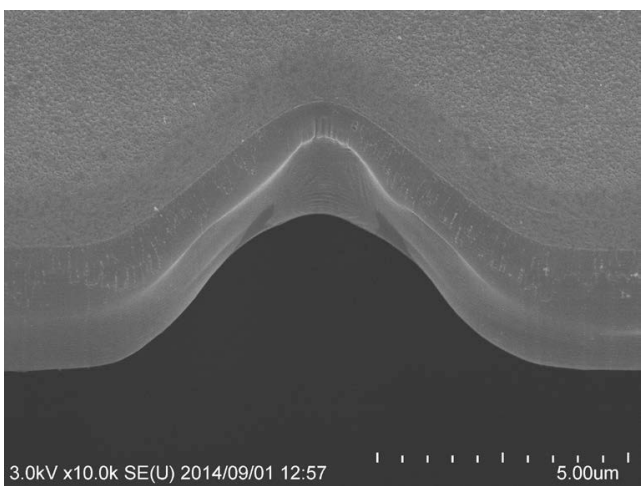

(i)

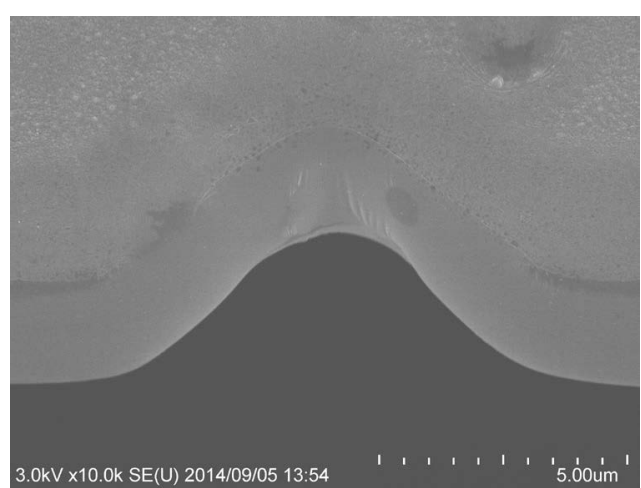

(j)

Figure 13. Sidewalls of fatigue test samples subjected to a) $0.8 \mathrm{~J} / \mathrm{cm}^{2}, 25$ pulses; b) $0.8 \mathrm{~J} / \mathrm{cm}^{2}, 1000$ pulses; c) $1.2 \mathrm{~J} / \mathrm{cm}^{2}, 10$ pulses; d) $1.2 \mathrm{~J} / \mathrm{cm}^{2}, 50$ pulses; e) $1.2 \mathrm{~J} / \mathrm{cm}^{2}, 100$ pulses; f) $1.2 \mathrm{~J} / \mathrm{cm}^{2}, 1000$ pulses; g) $1.6 \mathrm{~J} / \mathrm{cm}^{2}, 10 \mathrm{pulses}$; h) $2 \mathrm{~J} / \mathrm{cm}^{2}, 10$ pulses; i) $2.4 \mathrm{~J} / \mathrm{cm}^{2}, 10$ pulses \& j) $3.2 \mathrm{~J} / \mathrm{cm}^{2}, 10$ pulses.

and top surfaces. No out-of-plane remnant deformation was observed which indicates that no stress gradient was present across the whole thickness of the specimen. According to the knowledge of the authors, this is the first successful laser irradiation procedure with thin freestanding structures at energies beyond melting $\left(0.5 \mathrm{~J} / \mathrm{cm}^{2}\right)$ and even ablation $\left(1.3 \mathrm{~J} / \mathrm{cm}^{2}\right)$ thresholds [30] with KrFexcimer laser.

\subsection{Significance of Localized Irradiation}

Localized treatment was the reason behind efficient exposure even at high laser energies reaching $4 \mathrm{~J} / \mathrm{cm}^{2}$. As mentioned earlier, preliminary trials with a laser spot that covered the whole chip carrying the resonators led to fracture of the fatigue test structures at much lower energies $\left(0.16 \mathrm{~J} / \mathrm{cm}^{2}\right)$. Fracture always occurred at the notch. It is thought that fracture occurred due to out of plane bending by the mechanical shock caused by the energies absorbed on the resonator mass. Although the expected temperature rise along the top surface due to $0.16 \mathrm{~J} / \mathrm{cm}^{2}$ of laser energy is about $200 \mathrm{~K}$, the sudden contraction and expansion can lead to vibrations. Although the calculated static deformation caused by the temperature rise is within nanometers, the expected acceleration of the top surface is within $10^{6}-10^{7} \mathrm{~m} / \mathrm{s}^{2}$ due to the pulse duration being $20 \mathrm{~ns}$ [30]-[32]. Since the fatigue test structures can be modeled as a beam with a fan shaped mass, such acceleration of the mass would cause a significantly high force and accordingly a bending moment that could lead to failure at such low energies. By using localized irradiation the mass was kept at room temperature and only the silicon beam was irradiated leading to a successful operation.

\subsection{Energy Domains and Associated Features}

Trends observed in surface morphologies of tensile and fatigue samples as functions of the energies and number of pulses are summarized in Figure 14. The following observations can be made regarding ranges of laser energies and associated features together with residual stresses and surface roughness:

Less than $1.6 \mathrm{~J} / \mathrm{cm}^{2}$, no improvement in sidewall roughness is observed. At a high number of pulses $(>100)$, sidewalls develop columnar structures. Since the ablation threshold is around $1.3 \mathrm{~J} / \mathrm{cm}^{2}$, such structures are thought to occur due to evaporation and deposition and they increase in length as the number of pulses increase. In case of the top surfaces of tensile test samples subjected to perpendicular irradiation, there is an increase in residual surface stresses and roughness.

From $1.6 \mathrm{~J} / \mathrm{cm}^{2}$ to $2.4 \mathrm{~J} / \mathrm{cm}^{2}$, a good compromise between notch distortion and sidewall roughness was achieved for fatigue test samples. Surface roughness and residual stresses for tensile samples surfaces subjected to perpendicular irradiation also improved.

From $2.4 \mathrm{~J} / \mathrm{cm}^{2}$ to $3.2 \mathrm{~J} / \mathrm{cm}^{2}$, scallops disappear totally from sidewalls however the notch radius increases significantly with laser energy. For perpendicular surface irradiation, the highest increase in surface roughness was observed within that domain due to particle deposition.

From $3.2 \mathrm{~J} / \mathrm{cm}^{2}$ to $4 \mathrm{~J} / \mathrm{cm}^{2}$, an improvement in surface roughness of tensile samples top surfaces subjected to perpendicular irradiation compared to as fabricated samples was achieved. Further improvement in residual sur- 


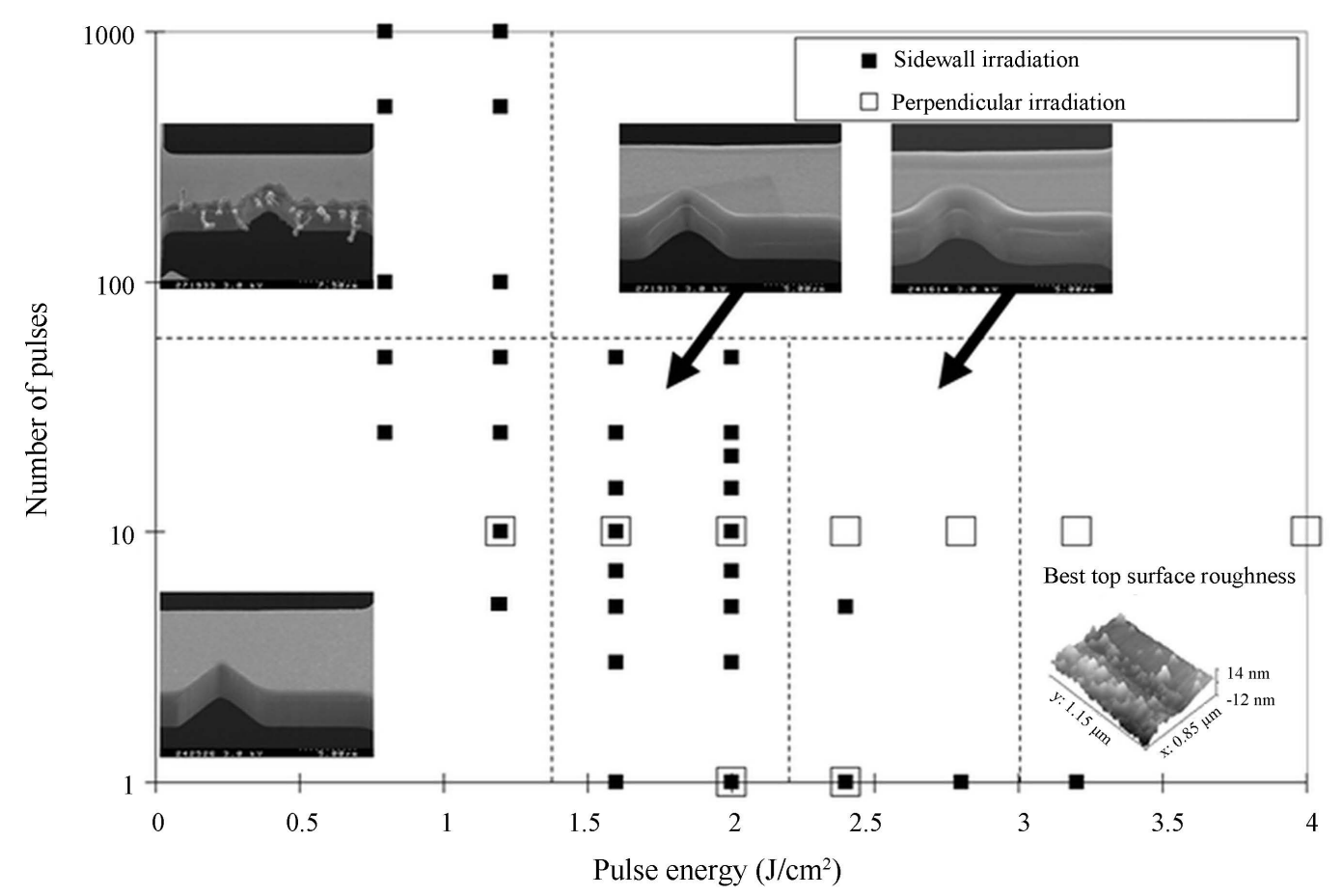

Figure 14. Summary of laser treatment results.

face stresses was also noticed.

Samples subjected to more than $4 \mathrm{~J} / \mathrm{cm}^{2}$ fractured.

\subsection{Effect of Laser Energy, Number of Pulses and Tilt Angles on Melt Flow}

Since the melting time is supposed to be within the nanosecond regime and that the time interval between each pulse is 1 second, it is suggested that the effect of the number of pulses is an accumulation in melting time with no heat accumulation or change in the maximum temperature with each pulse. The laser energy on the other hand would be effective to increase the maximum temperature, the melting time, and depth, which decreases viscosity and enhances the flow of the molten silicon. This explains why the laser energy is more significant in liquid flow than the number of pulses as was indicated by the flow of liquid front indicated by the white line on sidewalls as seen in Figure 13. This could also explain the more significant increase in notch radius of fatigue test samples with laser energy and the more skewed mass distribution along sidewalls as the tilt angle increases since a higher tilt angle means more laser energy absorbed leading to a higher melt depth and lower viscosity causing more mass being displaced towards the bottom edge of sidewalls.

In total, the surface morphology of irradiated surfaces is that of the liquid which gets solidified after a melting time depending on the laser energy and number of pulses. Laser energy enhances the flow more significantly than the number of pulses because of the higher maximum temperature, which causes a decrease in viscosity and increase in molten region, but the main contribution of the number of pulses would be to increase the total melting time. So for surfaces that need no precise control on dimensions or profiles, an irradiation with higher laser energy could be efficient for improving surface roughness but for surfaces requiring preservation of their original shape, multiple shots at lower laser energies might be a better approach.

\section{Conclusion}

Localized laser treatment with energies up to $4 \mathrm{~J} / \mathrm{cm}^{2}$ was successful in improving surface roughness of sidewalls and top surfaces of freestanding structures without fracture in order to improve mechanical performance. Laser energies between $1.6 \mathrm{~J} / \mathrm{cm}^{2}$ and $2.4 \mathrm{~J} / \mathrm{cm}^{2}$ could be used for sidewall irradiation of fatigue test samples since the notch profile needs to be preserved while achieving acceptable roughness. Higher values of energies between $2.4 \mathrm{~J} / \mathrm{cm}^{2}$ and $4 \mathrm{~J} / \mathrm{cm}^{2}$ could be used for sidewall irradiation of tensile test samples since scallops totally 
disappear even with single pulses. Energy values between $3.2 \mathrm{~J} / \mathrm{cm}^{2}$ and $4 \mathrm{~J} / \mathrm{cm}^{2}$ could be considered for perpendicular irradiation of top surfaces of tensile test samples since an improvement in roughness was achieved compared to fabricated samples together with an improvement in crystallinity and developed surface stresses.

\section{References}

[1] Yi, T., Li, L. and Kim, C.J. (2000) Microscale Material Testing of Single Crystalline Silicon: Process Effects on Surface Morphology and Tensile Strength. Sensors and Actuators A: Physical, 83, 172-178. http://dx.doi.org/10.1016/S0924-4247(00)00350-2

[2] Pierron, O.N. and Muhlstein, C.L. (2006) The Critical Role of Environment in Fatigue Damage Accumulation in DeepReactive Ion-Etched Single-Crystal Silicon Structural Films. Journal of Microelectromechanical Systems, 15, 111-119. http://dx.doi.org/10.1109/JMEMS.2005.863602

[3] Alsem, D.H., Boyce, B.L., Stach, E.A. and Ritchie, R.O. (2008) Effect of Post-Release Sidewall Morphology on the Fracture and Fatigue Properties of Polycrystalline Silicon Structural Films. Sensors and Actuators A: Physical, 147, 553-560. http://dx.doi.org/10.1016/j.sna.2008.05.027

[4] Liang, E.Z., Hung, S.C., Hsieh, Y.P. and Lin, C.F. (2008) Effective Energy Densities in KrF Excimer Laser Reformation as a Sidewall Smoothing Technique. Journal of Vacuum Science \& Technology B, 26, 110-116. http://dx.doi.org/10.1116/1.2825163

[5] Hung, S.C., Liang, E.Z. and Lin, C.F. (2009) Silicon Waveguide Sidewall Smoothing by KrF Excimer Laser Reformation. Journal of Lightwave Technology, 27, 887-892. http://dx.doi.org/10.1109/JLT.2008.923240

[6] Yan, J.W., Asami, T. and Kuriyagawa, T. (2009) Complete Recovery of Subsurface Structures of Machining-Damaged Single Crystalline Silicon by Nd: YAG Laser Irradiation. Key Engineering Materials, 389, 469-474. http://dx.doi.org/10.4028/www.scientific.net/KEM.389-390.469

[7] Yan, J., Sakai, S., Isogai, H. and Izunome, K. (2009) Recovery of Microstructure and Surface Topography of GrindingDamaged Silicon Wafers by Nanosecond-Pulsed Laser Irradiation. Semiconductor Science and Technology, 24, Article ID: 105018. http://dx.doi.org/10.1088/0268-1242/24/10/105018

[8] Bosseboeuf, A., Boulmer, J. and Débarre, D. (1997) Planarization of Rough Silicon Surfaces by Laser Annealing. Applied Surface Science, 109, 473-476. http://dx.doi.org/10.1016/S0169-4332(96)00922-1

[9] Kim, S.G., Roh, T.M., Kim, J., et al. (2003) Behavior of Trench Surface by $\mathrm{H}_{2}$ Annealing for Reliable Trench Gate Oxide. Journal of Crystal Growth, 255, 123-129. http://dx.doi.org/10.1016/S0022-0248(03)01238-7

[10] Lee, M.C.M., and Wu, M.C. (2006) Thermal Annealing in Hydrogen for 3-D Profile Transformation on Silicon-onInsulator and Sidewall Roughness Reduction. Journal of Microelectromechanical Systems, 15, 338-343. http://dx.doi.org/10.1109/JMEMS.2005.859092

[11] Takahashi, J.I., Tsuchizawa, T., Watanabe, T. and Itabashi, S.I. (2004) Oxidation-Induced Improvement in the Sidewall Morphology and Cross-Sectional Profile of Silicon Wire Waveguides. Journal of Vacuum Science and Technology B: Microelectronics and Nanometer Structures, 22, 2522-2525. http://dx.doi.org/10.1116/1.1800359

[12] Sparacin, D.K., Spector, S.J. and Kimerling, L.C. (2005) Silicon Waveguide Sidewall Smoothing by Wet Chemical Oxidation. Journal of Lightwave Technology, 23, 2455-2461. http://dx.doi.org/10.1109/JLT.2005.851328

[13] Rogers, J.W. and Phinney, L.M. (2004) Temperature Response of Silicon MEMS Cantilevers during and after Nd: YAG Laser Irradiation. Numerical Heat Transfer, Part A: Applications, 45, 737-750. http://dx.doi.org/10.1080/10407780490440110

[14] Rogers, J.W. and Phinney, L.M. (2001) Process Yields for Laser Repair of Aged, Stiction-Failed, MEMS Devices. Journal of Microelectromechanical System, 10, 280-285. http://dx.doi.org/10.1109/84.925783

[15] Zhang, X.R. and Xu, X. (2005) Laser Bending for High-Precision Curvature Adjustment of Microcantilevers. Applied Physics Letters, 86, Article ID: 021114. http://dx.doi.org/10.1063/1.1851617

[16] Dirscherl, M., Esser, G. and Schmidt, M. (2006) Ultrashort Pulse Laser Bending. Journal of Laser Micro/Nanoengineering, 1, 54-60. http://dx.doi.org/10.2961/jlmn.2006.01.0011

[17] Mitwally, M.E., Tsuchiya, T., Tabata, O. and Sedky, S. (2014) Improvement of Tensile Strength of Freestanding Single Crystal Silicon Microstructures Using Localized Harsh Laser Treatment. Japanese Journal of Applied Physics, 53, Article ID: 06JM03. http://dx.doi.org/10.7567/JJAP.53.06JM03

[18] Tsuchiya, T., Shikida, M. and Sato, K. (2002) Tensile Testing System for Sub-Micrometer Thick Films. Sensors and Actuators A: Physical, 97, 492-496. http://dx.doi.org/10.1016/S0924-4247(01)00862-7

[19] Ikehara, T. and Tsuchiya, T. (2008) High-Cycle Fatigue of Micromachined Single-Crystal Silicon Measured Using High-Resolution Patterned Specimens. Journal of Micromechanics and Microengineering, 18, Article ID: 075004. http://dx.doi.org/10.1088/0960-1317/18/7/075004 
[20] Alsem, D.H., Pierron, O.N., Stach, E.A., Muhlstein, C.L. and Ritchie, R.O. (2007) Mechanisms for Fatigue of Micron-Scale Silicon Structural Films. Advanced Engineering Materials, 9, 15-30. http://dx.doi.org/10.1002/adem.200600269

[21] Darif, M., Semmar, N. and Orléans Cedex, F. (2008) Numerical Simulation of Si Nanosecond Laser Annealing by COMSOL Multiphysics. Proceedings of the COMSOL Conference, Hannover, 2008.

[22] Anthony, T.R. and Cline, H.E. (1977) Surface Rippling Induced by Surface-Tension Gradients during Laser Surface Melting and Alloying. Journal of Applied Physics, 48, 3888-3894. http://dx.doi.org/10.1063/1.324260

[23] Amutha, G., Palani, I.A., Vasa, N.J., Singaperumal, M. and Okada, T. (2013) Investigations on Nano- and Pico-Second Laser Based Annealing Combined Texturing of Amorphous Silicon Thin Films for Photovoltaic Applications. Journal of Solid Mechanics and Materials Engineering, 7, 206-216. http://dx.doi.org/10.1299/jmmp.7.206

[24] Palani, I.A., Vasa, N.J., Singaperumal, M. and Okada, T. (2010) Investigation on Laser-Annealing and Subsequent Laser-Nanotexturing of Amorphous Silicon (a-Si) Films for Photovoltaic Application. Journal of Laser Micro/Nanoengineering, 5, 150-155. http://dx.doi.org/10.2961/jlmn.2010.02.0010

[25] Nayak, B.K., Sun, K., Rothenbach, C. and Gupta, M.C. (2011) Self-Organized 2D Periodic Arrays of Nanostructures in Silicon by Nanosecond Laser Irradiation. Applied Optics, 50, 2349-2355. http://dx.doi.org/10.1364/AO.50.002349

[26] De Wolf, I. (1996) Micro-Raman Spectroscopy to Study Local Mechanical Stress in Silicon Integrated Circuits. Semiconductor Science and Technology, 11, 139-154. http://dx.doi.org/10.1088/0268-1242/11/2/001

[27] Steen, W.M., Mazumder, J. and Watkins, K.G. (2003) Laser Material Processing. 3rd Edition, Springer-Verlag, London. http://dx.doi.org/10.1007/978-1-4471-3752-8

[28] Pedraza, A.J., Fowlkes, J.D. and Lowndes, D.H. (1999) Silicon Microcolumn Arrays Grown by Nanosecond PulsedExcimer Laser Irradiation. Applied Physics Letters, 74, 2322-2324. http://dx.doi.org/10.1063/1.123838

[29] Sanchez, F., Morenza, J.L., Aguiar, R., Delgado, J.C. and Varela, M. (1996). Whiskerlike Structure Growth on Silicon Exposed to ArF Excimer Laser Irradiation. Applied Physics Letters, 69, 620-622. http://dx.doi.org/10.1063/1.117926

[30] Kudryashov, S.I. and Allen, S.D. (2002) Photoacoustic Study of KrF Laser Heating of Si: Implications for Laser Particle Removal. Journal of Applied Physics, 92, 5627-5631. http://dx.doi.org/10.1063/1.1503859

[31] Tam, A.C., Leung, W.P., Zapka, W. and Ziemlich, W. (1992) Laser-Cleaning Techniques for Removal of Surface Particulates. Journal of Applied Physics, 71, 3515-3523. http://dx.doi.org/10.1063/1.350906

[32] Park, H.K., Grigoropoulos, C.P., Leung, W.P. and Tam, A.C. (1994) A Practical Excimer Laser-Based Cleaning Tool for Removal of Surface Contaminants. IEEE Transactionson on Components, Packaging and Manufacturing Technology, Part A, 17, 631-643. http://dx.doi.org/10.1109/95.335050 
Scientific Research Publishing (SCIRP) is one of the largest Open Access journal publishers. It is currently publishing more than 200 open access, online, peer-reviewed journals covering a wide range of academic disciplines. SCIRP serves the worldwide academic communities and contributes to the progress and application of science with its publication.

Other selected journals from SCIRP are listed as below. Submit your manuscript to us via either submit@scirp.org or Online Submission Portal.
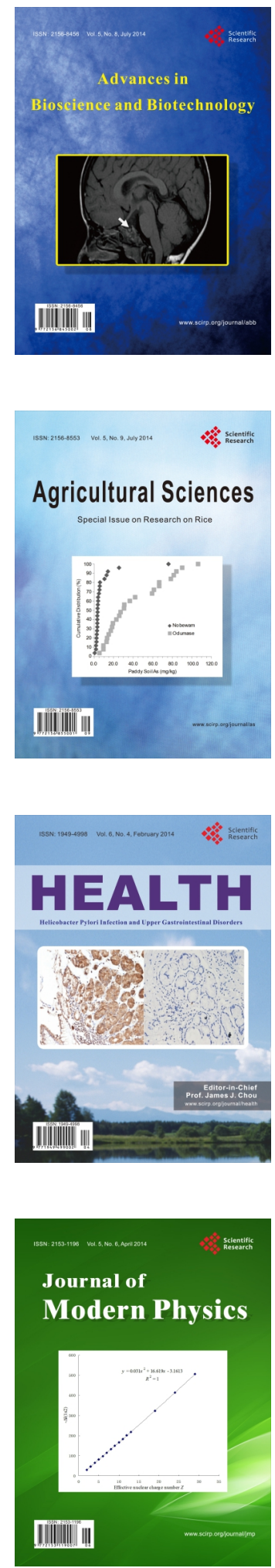
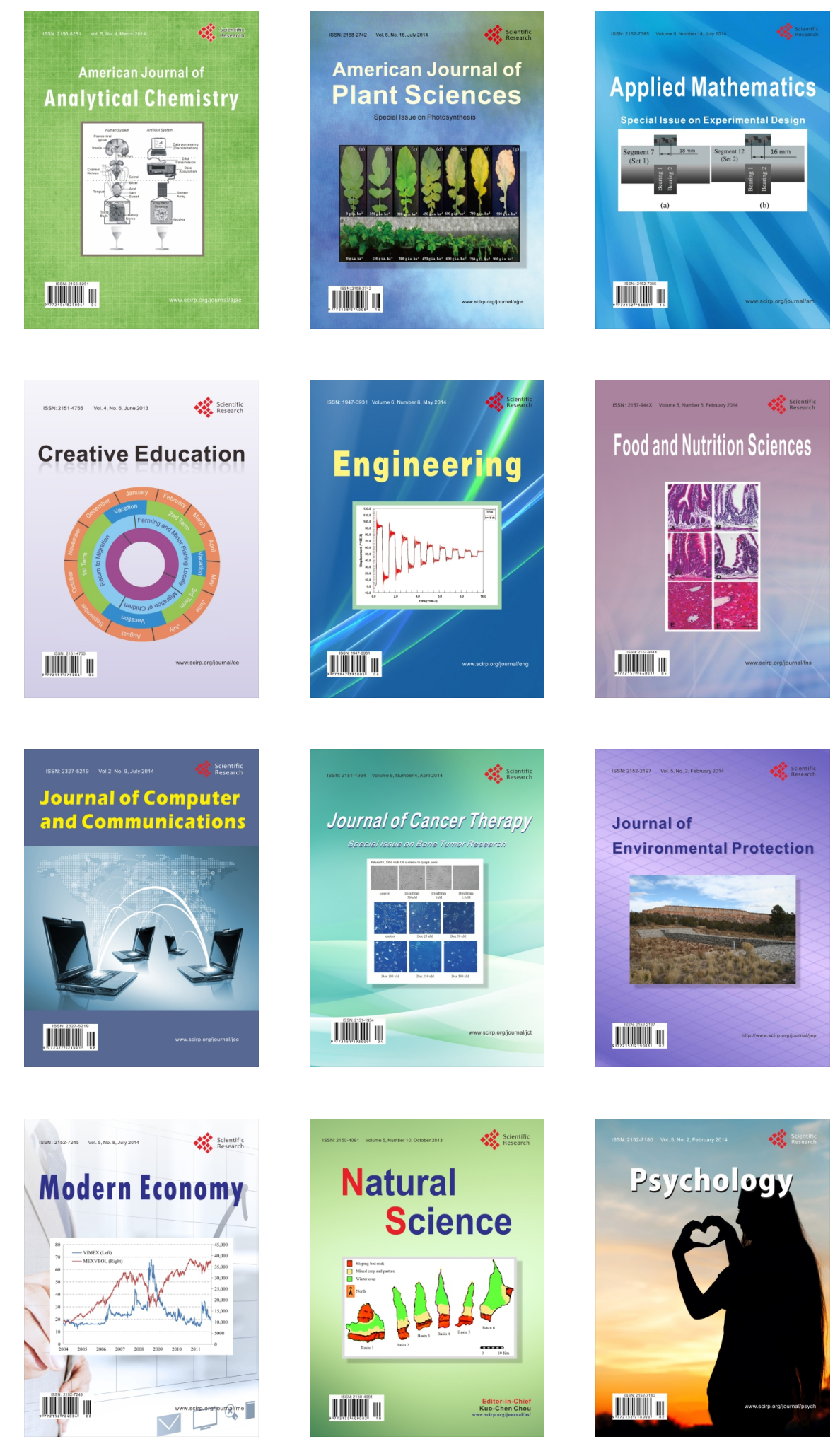